Applications of Surface Science 7 (1981) 206-214

North-Holland Publishing Company

\title{
AN AES AND LEED STUDY OF CARBON AND OXYGEN SORPTION ON COPPER SURFACES
}

\author{
O. ODA *, L.J. HANEKAMP and G.A. BOOTSMA \\ Department of Applied Physics, Twente University of Technology, \\ 7500 AE Enschede, The Netherlands
}

Received 15 July 1980

Revised manuscript received 20 October 1980

The sorption of carbon and oxygen on copper surfaces has been studied by AES and LEED. The carbon coverage has been estimated by measuring the substrate Auger peak attenuation upon changing the carbon coverage and by studying the coadsorption of oxygen and carbon on the surface. The effect of carbon on the background of derivative spectra is also reported.

\section{Introduction}

In cleaning copper surfaces by ion bombardment and annealing, carbon appears very often as a final contaminant which is very difficult to eliminate totally compared with other contaminants $(\mathrm{O}, \mathrm{S}, \mathrm{Cl})$. Even during ion bombardment, surfaces are easily contaminated by carbon and the degree of contamination depends on the cleaning conditions. The main cause of the contamination may be the decomposition of hydrocarbons of the residual gas $[1,2]$.

In spite of this frequently occurring contamination by carbon, to our knowledge systematic studies of carbon on copper surfaces have not been published. Only a LEED observation of a carbon superstructure on $\mathrm{Cu}(100)$ [2] and a metal deposition study on $\mathrm{Cu}(100)$, contaminated by carbon [3] have been reported. In this paper we present results of a LEED-AES study on $\mathrm{Cu}(111)$ and $\mathrm{Cu}(110)$, both at different carbon coverages. To estimate the carbon coverage the co-adsorption of oxygen on $\mathrm{Cu}(110)$ covered by carbon was also studied.

In contrast with carbon, the adsorption of oxygen on copper surfaces has been extensively studied by many authors using various surface analytical techniques, such as LEED, AES, XPS, UPS, ELS, ellipsometry and work function measurements. For recent reviews cf. refs. $[4,5]$. In this paper additional data on the adsorption of oxygen on $\mathrm{Cu}(110)$, obtained by LEED and AES, are reported.

\footnotetext{
* Research-fellow at Twente University of Technology.
} 


\section{Experimental}

The experiments were performed in an ion pumped stainless steel vacuum system with a LEED/AES four grid optics. The vacuum pressure after bake-out was $\sim 2 \times 10^{-10}$ Torr. A quadrupole gas analyzer (RIBER, model QX-100) was used for residual gas analysis. To perform dynamically cleaning and exposure cycles, the gas could be pumped by a turbo-molecular pump (Pfeiffer, model TPU 270). During these cycles the ion pump was separated from the system by a valve. The pressure was measured with an ionization gauge, for pressures $>10^{-5}$ Torr a Milli Torr gauge (Varian, model 971-5009) was used.

The single crystals were cut by spark erosion from $5 \mathrm{~N}$ copper rods (Metal Research Imanco) to within $0.5^{\circ}$ of the desired crystallographic orientation. The specimens were mechanically and electrochemically polished and mounted in the sample holder (RIBER, TUM-3). The specimen temperature was measured with a chromel alumel thermocouple attached to the specimen.

After mounting the sample, carbon, sulphur and oxygen contaminations were observed by AES. The AES spectra were taken with a retarding grid analyzer (RIBER, model OPR-304) using a primary energy of $2.5 \mathrm{keV}$ at a grazing incidence angle of $\approx 18^{\circ}$ and a modulation voltage of $10 \mathrm{~V}_{\mathrm{pp}}$. After several argon ion bombardments $\left(5 \times 10^{-5}\right.$ Torr, $\left.600 \mathrm{eV}\right)$ at room temperature only carbon was observed as contaminant. Sulphur segregation at higher temperatures could be eliminated by repeated cycles of argon bombardment and annealing $\left(\approx 500^{\circ} \mathrm{C}\right)$. After this treatment no sulphur contamination was observed up to $400^{\circ} \mathrm{C}$.

The different carbon coverages were obtained by reducing the carbon contamination by varying the argon bombardment conditions $\left(5-30 \mathrm{~min}, 25-400^{\circ} \mathrm{C}\right)$. For oxygen adsorption studies, research grade oxygen gas (Precigaz A48, $1^{\prime}$ Air Liquide) was introduced dynamically into the system at pressures between $10^{-8}$ and $10^{-4}$ Torr. During the exposures the ionization gauge and other filaments were switched off. After exposure the oxygen was pumped out before the measurements were performed.

\section{Results and discussion}

\subsection{Sorption of carbon}

For various carbon coverages $\left(0<h_{\mathrm{C}} / h_{\mathrm{Cu}}<0.41\right)$ the copper Auger peak height at $62 \mathrm{eV}\left(h_{\mathrm{Cu}}\right)$ and carbon Auger peak height at $272 \mathrm{eV}\left(h_{\mathrm{C}}\right)$ were measured for the $\mathrm{Cu}(111)$ surface as a function of the current between sample and ground. In the range of $0.5-6.0 \mu \mathrm{A}$ both peaks increased linearly with increasing current. This linearity has also been reported for clean copper surfaces [6]. The absolute peak height could be reproduced within $\pm 3 \%$ by taking special care of the sample position and the current between sample and ground. 


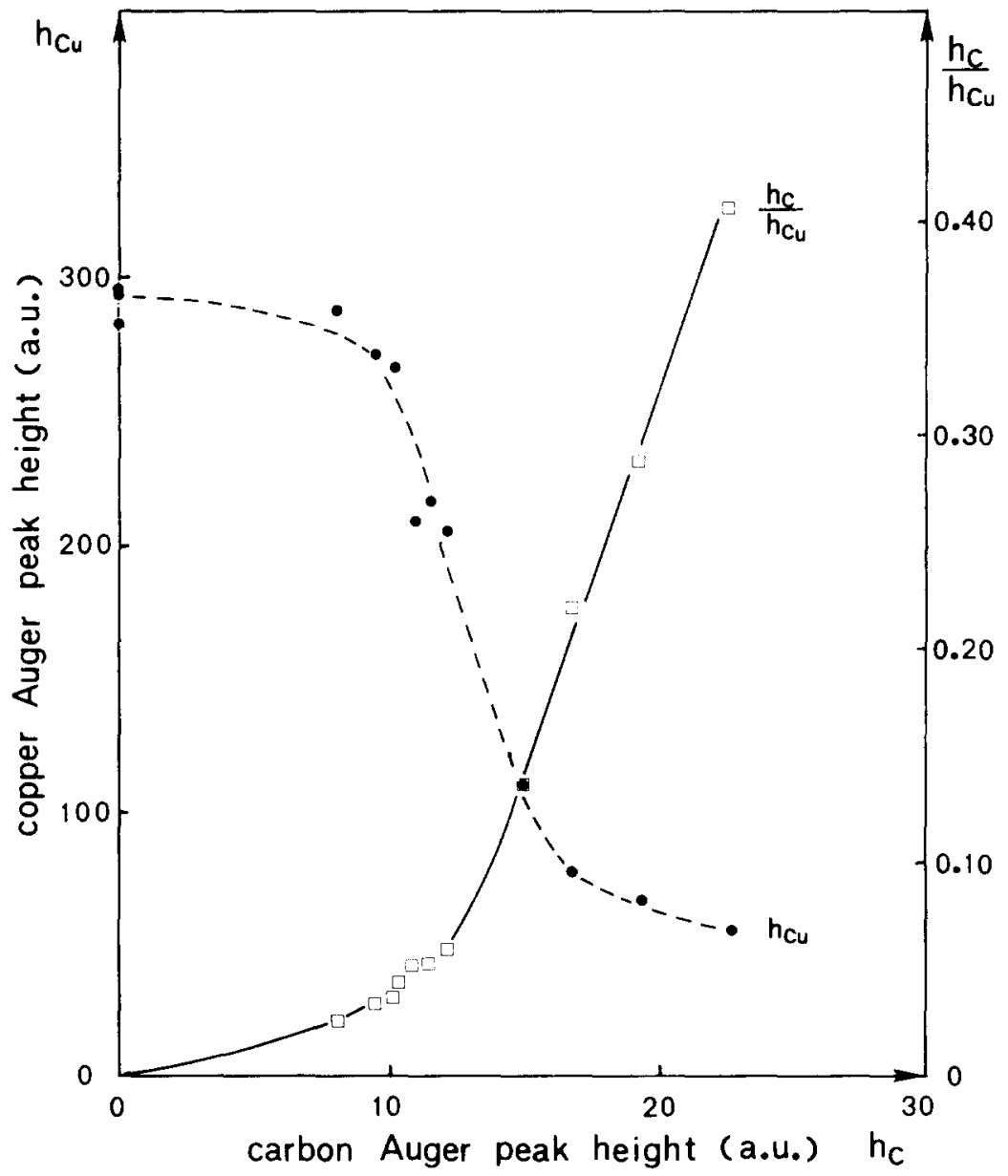

Fig. 1. The copper Auger peak height $\left(h_{\mathrm{Cu}}, 62 \mathrm{eV}\right)$ and the ratio $h_{\mathrm{C}} / h_{\mathrm{Cu}}$ as a function of the carbon Auger peak height $\left(h_{\mathrm{C}}, 272 \mathrm{eV}\right)$ for the $\mathrm{Cu}(111)$ surface.

In fig. 1 the copper Auger peak height and the ratio $h_{\mathrm{C}} / h_{\mathrm{Cu}}$ are plotted as a function of the carbon peak height. The plots were obtained by taking the values at $3.0 \mu \mathrm{A}$ of the measured linear curves. The figure shows that the copper Auger peak is not so much attenuated up to $h_{\mathrm{C}} / h_{\mathrm{Cu}} \approx 0.03$, while in the range $0.03<h_{\mathrm{C}} / h_{\mathrm{Cu}}$ $<0.14$ the attenuation is considerable. At higher carbon contaminations, the attenuation becomes smaller. The measurements on $\mathrm{Cu}(110)$ made in the range of 0.03 $<h_{\mathrm{C}} / h_{\mathrm{Cu}}<0.09$ also showed a considerable attenuation of the copper Auger peak. In the range of observed carbon contaminations, the shape of the carbon peak was that of graphite [7] and the width of the copper Auger peak remained constant. 
The results may be explained by assuming that on $\mathrm{Cu}(111)$ at lower carbon coverages $\left(h_{\mathrm{C}} / h_{\mathrm{Cu}}<0.03\right)$ carbon is present in the form of small multilayer islands (Volmer-Weber mode, cf. ref. [8]) and at higher coverages up to $h_{\mathrm{C}} / h_{\mathrm{Cu}} \approx 0.14$, the rest of the copper surface is covered by a uniform monolayer of carbon. The smaller attenuation at $h_{\mathrm{C}} / h_{\mathrm{Cu}}>0.14$ can be ascribed to the formation of a second layer. For an adsorbate present in the form of islands instead of a uniform adsorption layer, the simple Auger signal analysis applicable to metal deposition [9] and segregation [10] can not be used. The observed smaller attenuation of $h_{\mathrm{Cu}}$ above $h_{\mathrm{C}} / h_{\mathrm{Cu}} \approx 0.14$ indicates that this value represents approximately the level of one "monolayer" of carbon (a surface totally covered by carbon).

The elastic mean free path (IMFP) of $62 \mathrm{eV}$ electrons as deduced from the least squares fit to the compiled data, given by Seah and Dench [11] is $\lambda_{\mathrm{m}}=1.8$ layers. This is in agreement with a recent determination of $\lambda_{m}=1.9$ layers for $64 \mathrm{eV}$ electrons through a carbon layer on platinum [1]. From the value $\lambda_{m}=1.8$ the attenu-

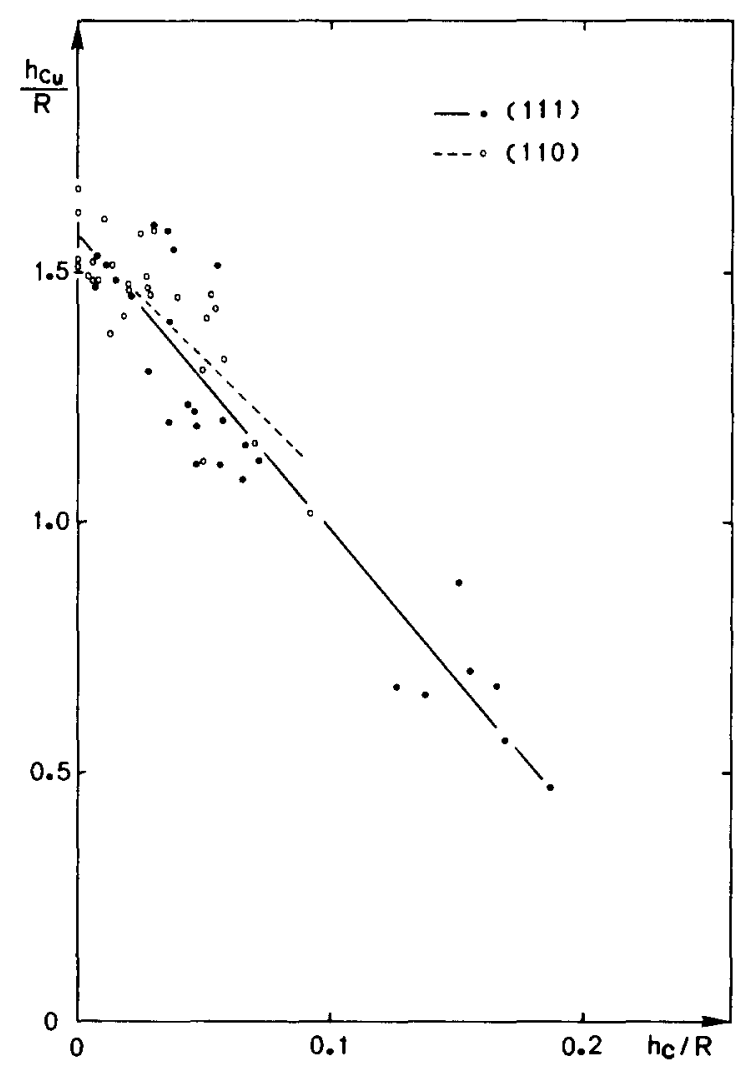

Fig. 2. $h_{\mathrm{Cu}} / R$ as a function of $h_{\mathrm{C}} / R . R$ is the distance between the midpoint of the copper Auger peak at $62 \mathrm{eV}$ and the constant background at higher energies. 
ation through one monolayer of adsorbate can be calculated to be $\alpha=0.47$ by using the equation $\alpha=\exp \left(-1 / 0.75 \lambda_{\mathrm{m}}\right)$ [1]. This value is near to the attenuation factor derived from fig. 1 at $h_{\mathrm{C}} / h_{\mathrm{Cu}} \approx 0.14$ which is 0.37 . This shows that our estimation of one monolayer is not unreasonable.

McDonnell et al. [12] have reported the presence of temperature dependent peaks (TDP) in secondary electron emission spectra. Because of the presence of a TDP at $270 \mathrm{eV}$, it was found that the carbon Auger peak is difficult to detect at lower coverages $h_{\mathrm{C}} / h_{\mathrm{Cu}}<0.01$.

In fig. 2 the effect of the carbon coverage on the background of the derivative spectrum is presented by plotting $h_{\mathrm{Cu}} / R$ as a function of $h_{\mathrm{C}} / R$, where $R$ is the distance between the midpoint of the copper Auger peak at $62 \mathrm{eV}$ and the constant background at higher energies.

As discussed in ref. [13] the value of $R$ can be considered as a parameter associated with the true secondary electron emission. It should be noted that $h_{\mathrm{Cu}} / R$ includes also the effect of carbon adsorption on the Auger signal [13]. Fig. 2 shows that the effect is the same for the two crystallographic orientations (111) and (110). The extrapolated values of $h_{\mathrm{Cu}} / R$ are for both clean $\mathrm{Cu}$ surfaces 1.57 . This value is near to that of nickel (1.72) [13], in spite of the difference in substrate. This might imply that the ratio of Auger electron emission and true secondary electron emission in the energy range of about $62 \mathrm{eV}$ is the same for nickel and copper.

For the (110) and (111) surfaces no extra LEED spots were observed at room temperature. The substrate spots were diffused and the background was intensified with increasing carbon coverage. This indicates that carbon is probably adsorbed in an amorphous disordered form, in contrast with $\mathrm{Cu}(100)$ [2]. At coverages $h_{\mathrm{C}} / h_{\mathrm{Cu}}$ $>0.14$ the substrate spots became nearly unobservable, indicating the formation of a uniform carbon layer as mentioned above.

\subsection{Sorption of oxygen on $\mathrm{Cu}(110)$}

Auger spectra for oxygen on clean $\mathrm{Cu}(110)$ surfaces were taken at room temperature in the oxygen exposure range of $0-10^{4} \mathrm{~L}\left(1 \mathrm{~L}=10^{-6}\right.$ Torr s). In fig. 3 , the ratio of the oxygen Auger peak height at $514 \mathrm{eV}$ to the copper Auger peak height at $62 \mathrm{eV}$ is shown as a function of the oxygen exposure. At about $45 \mathrm{~L}$, the surface was saturated by oxygen and a $(2 \times 1)$ structure was observed by LEED. The oxygen Auger signal remained constant in the range of $45-3 \times 10^{3} \mathrm{~L}$ and increased above $3 \times 10^{3} \mathrm{~L}$. At $3 \times 10^{4} \mathrm{~L}$, a very vague $\mathrm{c}(6 \times 2)$ structure was observed. A sharp $\mathrm{c}(6 \times 2)$ structure was obtained by exposing the surface to oxygen at $200^{\circ} \mathrm{C}$.

The observed kinetic character is similar to the results of Habraken and Bootsma [14], who measured the Auger peak height of copper at $920 \mathrm{eV}$ instead of $62 \mathrm{eV}$. The observed constant coverage in the range of $45-3 \times 10^{3} \mathrm{~L}$ may be ascribed to a nucleation process prior to the formation of the $c(6 \times 2)$ structure as has been observed for $\mathrm{Cu}(100)$ [15]. As the equilibrium oxygen pressure for bulk oxide formation at room temperature is less than $10^{-43}$ Torr [16], the observed constant coverage can not be due to an equilibrium process. 


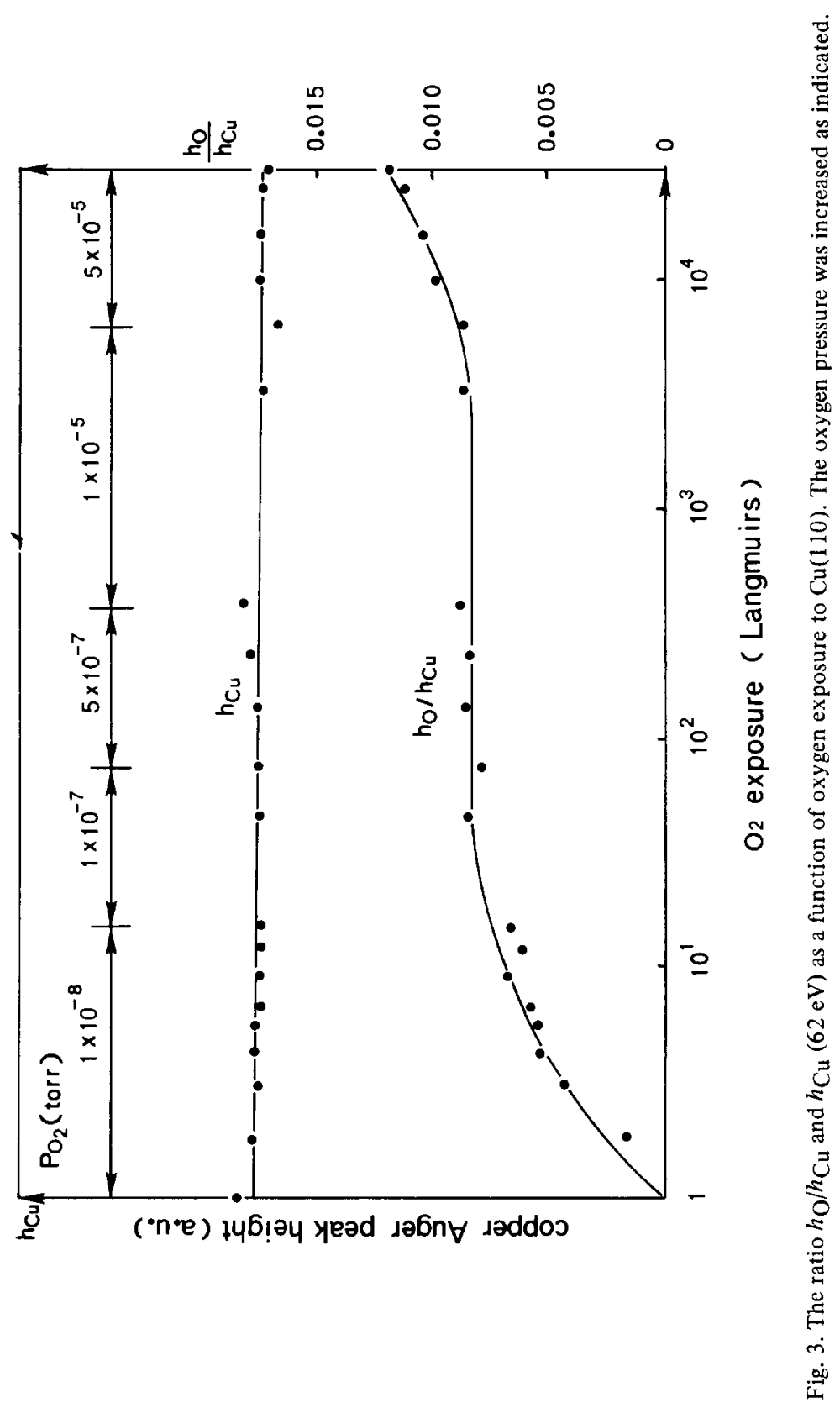




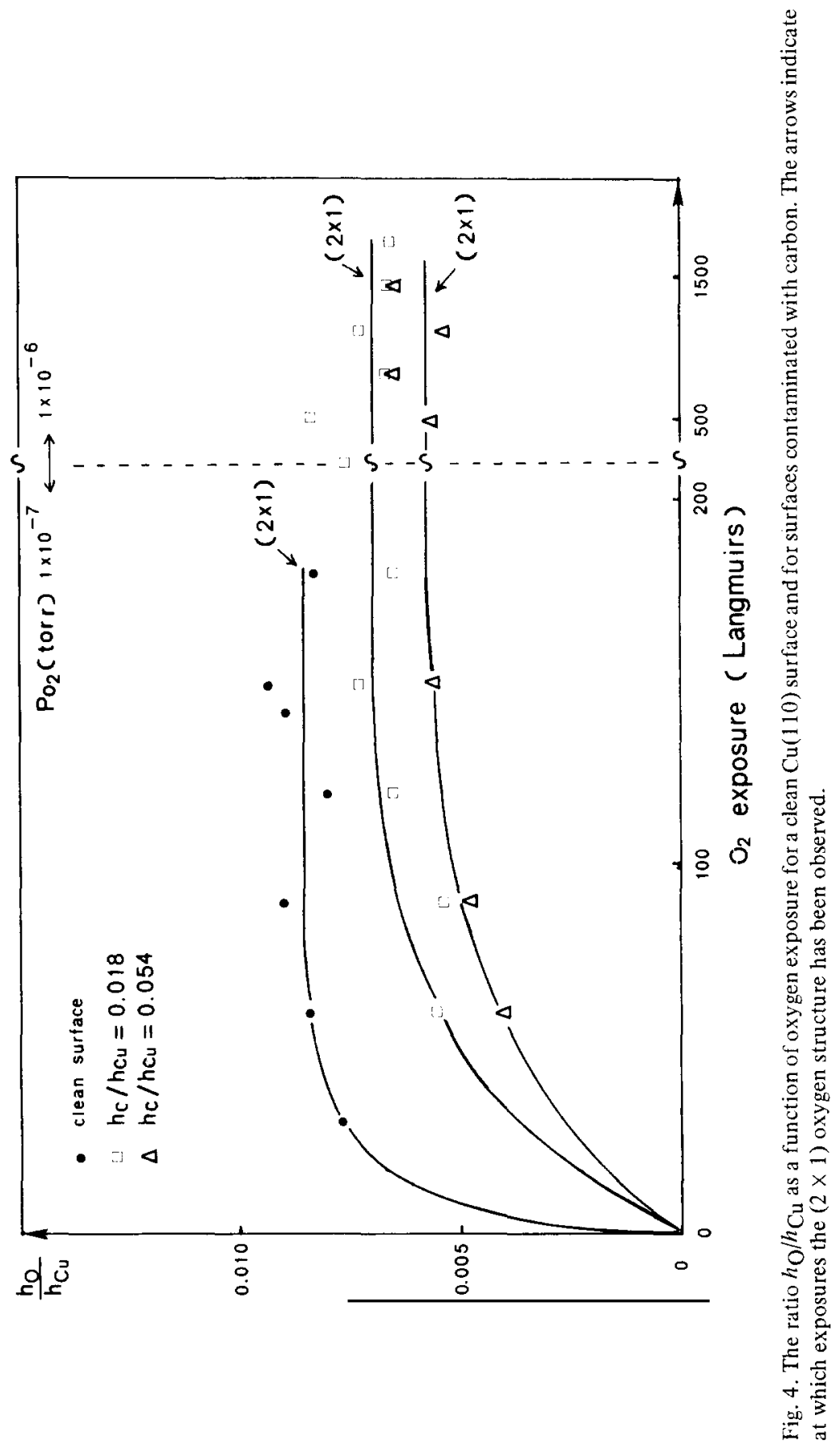


The copper peak height at $62 \mathrm{eV}$ was measured after various oxygen exposures while the sample was fixed at the same position and with a constant current between sample and ground of $3 \mu \mathrm{A}$. As shown in fig. 3, the peak height remains practically constant, even at exposures up to $5 \times 10^{4} \mathrm{~L}$. The result shows that the substrate Auger peak is not attenuated by oxygen adsorption even though the Auger electron energy is in the range of the minimum IMFP [11]. A similar effect has been reported for sulphur on copper [9] and phosphorus on nickel [10]. The IMFP curves as a function of electron energy [11] seem not to be valid for these adsorption systems. This could be caused either by incorporation of the adsorbed atoms or because of exceptional scattering mechanisms.

\subsection{Co-adsorption of carbon and oxygen on $\mathrm{Cu}(110)$}

Oxygen was adsorbed on a $\mathrm{Cu}(110)$ surface covered by various carbon quantities. As shown in fig. 4 , the oxygen saturation coverage for the $(2 \times 1)$ structure decreases and the adsorption rate is retarded by increasing the carbon coverage. A similar phenomenon has been observed for adsorption of oxygen on nickel covered by carbon [17]. After saturation, the $(2 \times 1)$ structure was always observed. This shows that the surface is partially covered by carbon with bare surface in between, which can be occupied by oxygen. The result supports the mechanism proposed in section 3.1 .

From fig. 4 , the carbon coverages $\theta_{C}$ can be estimated. The Auger peak ratios at oxygen saturation coverages on the clean and carbon contaminated surfaces will be represented by $h_{\mathrm{O}}^{0} / h_{\mathrm{Cu}}^{0}$ and $h_{\mathrm{O}} / h_{\mathrm{Cu}}$, respectively. The ratio $\left(h_{\mathrm{O}}^{0} / h_{\mathrm{O}}\right) /\left(h_{\mathrm{Cu}} / h_{\mathrm{Cu}}^{0}\right)$ can be derived from fig. 4 . The Auger signal $h_{\mathrm{Cu}}$ is attenuated by the presence of carbon (fig. 1) but not by adsorption of oxygen (fig. 3). If $h_{\mathrm{Cu}}^{*}$ is the value of $h_{\mathrm{Cu}}$ corrected for the attenuation by carbon, $\theta_{\mathrm{C}}$ is calculated from $1-\theta_{\mathrm{C}}=\left(h_{\mathrm{O}} / h_{\mathrm{O}}^{0}\right)$ / $\left(h_{\mathrm{Cu}}^{*} / h_{\mathrm{Cu}}^{0}\right)$. The data in fig. 4 yield: $\theta_{\mathrm{C}} \approx 0.19\left(h_{\mathrm{C}} / h_{\mathrm{Cu}}=0.018\right)$ and $\theta_{\mathrm{C}} \approx 0.51\left(h_{\mathrm{C}} /\right.$ $h_{\mathrm{Cu}}=0.054$ ). The values $h_{\mathrm{C}} / h_{\mathrm{Cu}}$ are measured prior to the oxygen exposure. By plotting $\theta_{\mathrm{C}}$ as a function of $h_{\mathrm{C}} / h_{\mathrm{Cu}}$ the estimated values are consistent with the result obtained from the measurement of the substrate Auger peak attenuation $\theta_{\mathrm{C}}$ $\approx 1.0\left(h_{\mathrm{C}} / h_{\mathrm{Cu}}=0.14\right)$.

\section{Conclusions}

The procedure of probing surface properties with adsorbed metal monolayers as described by Rhead [8] was applied to sorption of carbon on copper surfaces. The AES measurements indicated the monolayer coverage and island formation at low coverages. By adsorbing oxygen on surfaces contaminated with carbon, the carbon coverage could be calibrated. 


\section{Acknowledgement}

The authors would like to thank Th.L. Schroote (State University of Utrecht) for the sample preparation and A.Th.B. Wikkerink, R.F. Hefti and H.J.M. Oerbekke for their technical assistance during the installation of the equipment.

\section{References}

[1] J.P. Biberian and G.A. Somorjai, Appl. Surface Sci. 2 (1979) 352.

[2] G.E. Rhead, CR Acad. Sci. Ser. C 268 (1969) 1817.

[3] C. Argile, Thesis, Université Pierre et Marie Curie (Paris, 1978).

[4] F.H.P.M. Habraken, E.Ph. Kieffer and G.A. Bootsma, Surface Sci. 83 (1979) 45.

[5] C. Benndorf, B. Egert, G. Keller, H. Seidel and F. Thieme, J. Phys. Chem. Solids 40 (1979) 877.

[6] M. Perdereau, Surface Sci. 24 (1971) 239.

[7] L.H. Jenkins and M.F. Chung, Surface Sci. 24 (1971) 125.

[8] G.E. Rhead, J. Vacuum Sci. Technol. 13 (1976) 603.

[9] C. Argile and G.E. Rhead, Surface Sci. 53 (1975) 659.

[10] O. Oda and G.E. Rhead, Surface Sci. 92 (1980) 467.

[11] M.P. Seah and W.A. Dench, Surface Interface Anal. 1 (1979) 2.

[12] L. McDonnell, B.D. Powell and D.P. Woodruff, Surface Sci. 40 (1973) 669.

[13] O. Oda, J. Electron Spectry. 18 (1980) 351.

[14] F.H.P.M. Habraken and G.A. Bootsma, Surface Sci. 87 (1979) 333.

[15] F.H.P.M. Habraken, C.M.A.M. Mesters and G.A. Bootsma, Surface Sci. 97 (1980) 264.

[16] R.A. Swalin, Thermodynamics of Solids (Wiley, New York, 1972).

[17] D.F. Mitchell, P.B. Sewell and M. Cohen, Surface Sci. 61 (1976) 355. 